women whose repeat smears after finding mild dyskaryosis are negative have cervical intraepithelial neoplasia on biopsy. Compromise is inevitable with inadequate colposcopy services in Britain, but compromise may sometimes mean death.

Professor of Reproductive Pathology,

H Fox

University of Manchester,

Manchester M13 9PT

1 Evans DMD, Hudson EA, Brown CL, et al. Terminology in gynaecological cytopathology: report of the working party of the British Society for Clinical Pathology. $\mathcal{F}$ Clin Pathol 1986;39:933-44. 2 Soutter WP, Wisdom S, Brough AK, Monaghan JM. Should patients with mild atypia in a cervica smear be referred for colposcopy? Br $\mathcal{F}$ Obstet Gynaecol 1986;93:70-4

Walker EM, Dodgson J, Duncan ID. Does mild atypia warrant further investigation? Lance 1986;ii:672-3.

4 Singer A. The abnormal cervical smear. Br Med f 1986;293:1551-6.

\section{Should sympathomimetics be available over the counter?}

The abuse of amphetamine and the resultant paranoid psychoses are well recognised, ${ }^{1}$ and similar problems may arise from the abuse of other sympathomimetics such as methylphenidate, diethylpropion, and phenmetrazine. ${ }^{2}$ Not surprisingly these drugs came to be made available only on prescription and were subsequently classed as controlled drugs. Nevertheless, sympathomimetic drugs such as ephedrine, pseudoephedrine, and phenylpropanolamine, which have similar propensities, remain available over the counter. ${ }^{3.5}$ They are common constituents in cough and cold remedies, which are by far the largest category of nonprescription sales in Britain, ${ }^{6}$ and which in overdose may be fatal.

In the United States the abuse of over the counter sympathomimetics has become recognised as a national problem, ${ }^{8-10}$ with terms such as pseudospeed, look alikes, and pea shooters. Pseudospeed is a generic term given to various combinations of non-prescription stimulants such as ephedrine, phenylpropanolamine, and caffeine.$^{10}$ Look alikes are the same stimulants packaged closely to resemble amphetamine tablets in size, colour, numbering, and trademark, enabling them to be sold on the street as such. Look alikes are said to have first appeared in the south eastern United States, where they were sold as amphetamines. ${ }^{9}$ During the 1970 s phenylpropanolamine was used increasingly as an over the counter appetite suppressant and was eventually incorporated into look alike drugs. ${ }^{8}$ By 1980 most look alikes contained ephedrine, phenylpropanolamine, and caffeine. They were manufactured in "garage laboratories" and sold cheaply by mail order. ${ }^{10}$ Four such look alike capsules might be as potent as a substantial dose of amphetamine. ${ }^{9}$

Congressional hearings held in 1981 and 1983 considered the pseudospeed problem but the Food and Drug Administration was unable to stop manufacture as these were over the counter drugs. They were, however, able to prevent counterfeiting controlled drugs and to seize look alikes. The look alike industry responded by changing the appearance of its products. The United States Postal Service then refused to deliver phenylpropanolamine, ephedrine, and caffeine on the grounds that the triple combination was not safe as advertised. In August 1983 the Food and Drug Administration banned its sale but the look alike industry removed one of the constituents, whereupon in December 1983 the Food and Drug Administration banned the combination of phenylpropanolamine and caffeine. Currently, legally produced pseudospeed contains only one sympathomimetic and is usually sold as an over the counter appetite suppressant. ${ }^{9}$ The growing popularity of cocaine in the United States and its high price have also resulted in pseudospeed being marketed as a substitute for cocaine with names such as "cokesnuff," "coca snow incense," and "poor man's cocaine." 112 Pseudospeed has been reported as the most commonly abused drug after alcohol and cannabis among adolescents in central New York. ${ }^{10}$ The pseudospeed industry has a multimillion dollar turnover, makes vast profits, and has always been one step ahead of any legislation designed to curb the drug.

Abuse of over the counter sympathomimetics is a major problem in the United States, and, like solvent abuse, it might cross the Atlantic. There is a strong case for making them available here only on prescription; this may help to prevent the development of abuse in the United Kingdom.

ANDREW WHITEHOUSE

Clinical Lecturer,

University Department of Psychiatry,

Addenbrooke's Hospital,

Cambridge CB2 2QQ

1 Connell PH. Amphetamine psychosis. London: Oxford University Press, 1958. (Maudsley Monographs No 5 .)

2 Ellinwood EH, Rockwell WJK. Central nervous systems stimulants and anorectic drugs. In: Dukes MHG, ed. Meyler's side effects of drugs. Vol X. Amsterdam: Elsevier, 1984:1-23.

Whitehouse AM, Duncan JM. Ephedrine psychosis rediscovered. Br f Psychiatry 1987; 150:258-61.

4 Leighton KM. Paranoid psychosis after abuse of Actifed. BrMed $\mathcal{F}$ 1982;284:789-90.

5 Wharton BK. Nasal decongestants and paranoid psychosis. Br f Psychiatry 1970;117:439-40.

6 Anonymous. Cough medicines (Editorial). Drug Ther Bull 1985;22:85-7.

7 Logie AW, Scott CM. Fatal overdose of phenylpropanolamine. Br Med f 1984;289:591.

8 Lake CR, Algana SW, Moriarty K, Quirk RS, Gamble E, Reid A. Use and abuse of look-alike stimulant drugs. Medical foumal of the United States Army 1985;42:16-20.

stimulant drugs. Medical foumal of the United States Army 1985;42:16-20. 1984;7:689-701.

10 Dougherty RJ. Pseudo-speed, look-alikes or pea-shooters. NY State 7 Med 1982;1:74-5.

11 Seigel RK. Cocaine substitutes. N Engl f Med 1982;302:817.

12 Mack RB. Are your patients speeding? NC Med f 1981;42:489.

\section{Special units for acute upper gastrointestinal bleeding}

The management of patients with acute upper gastrointestinal bleeding remains controversial, partly because of different and sometimes conflicting medical interests. Endoscopists have reported that endoscopy is better than radiology, ${ }^{1}$ radiologists that radiology is better than endoscopy, ${ }^{2}$ surgeons that an early operation reduces mortality, ${ }^{3}$ and physicians that an early operation increases mortality. ${ }^{4}$ We must therefore look closely at a claim from an Australian hospital that setting up a special multidisciplinary unit reduced mortality from acute upper gastrointestinal bleeding from $15 \%$ to $6 \%$ in a few years. ${ }^{5}$

Mortality in patients admitted to hospital with acute upper gastrointestinal bleeding has remained fairly constant at around $10 \%$ over the past 40 years, although the proportion of elderly patients has increased enormously. ${ }^{6}$ As many as two thirds of patients are now over 60 , and a quarter over 80 . Deaths are virtually confined to these elderly patients, ${ }^{8}$ and the death rate is not the same in all hospitals. In a recent study from a peripheral district general hospital the mortality was $15 \%,{ }^{9}$ whereas in teaching hospitals it is often substantially 
less than $10 \%$. Such differences could be because of different methods of including patients. Mortality is, however, likely to improve in hospitals where a special interest is taken in these patients.

Should special units for patients with acute upper gastrointestinal bleeding be established in district general hospitals? About 50000 such patients are admitted to hospital annually in Britain; an average district general hospital might therefore expect four or five such admissions a week, too few to justify a special unit. Furthermore, the proposal aims at reducing mortality, and as deaths are virtually confined to elderly patients the logic would be that the units should be particularly reserved for the elderly. Even if the resources for such developments were available few would argue that this would be sensible medicine.

There are, however, important lessons to be learnt from the experience of the special units. Perhaps their most important virtue is the improved collaboration between physicians and surgeons. Audit is also easier. The Australians consider that early endoscopy is important,${ }^{5}$ and, although in Britain patients investigated endoscopically and radiologically show no differences in mortality ${ }^{10}$ more recent data show that the prognostic value of endoscopy is likely to have an important impact on management. Thus ulcers with visible vessels in their base have a high incidence of serious rebleeding (and so patients often need an operation), whereas those without stigmata rarely rebleed. ${ }^{11.12}$

We cannot be complacent about managing acute upper gastrointestinal bleeding, and the results in district general hospitals may be worse than is realised. Most hospitals now have a physician with an interest in gastroenterology, who could improve the management of these patients. A first step would be to review results in individual hospitals, both retrospectively and prospectively from endoscopy records. Endoscopy is clearly the best investigation, and in most patients is best done on the morning after admission. This service should be easily organised in most district general hospitals and will provide as high a diagnostic yield as more urgent investigation. ${ }^{13}$ The few patients whose bleeding is very severe and continuous may need more urgent investigation.

A surgical policy needs to be established in each hospital, bearing in mind that there are no controlled data to guide us. When surgery is performed rarely or very often harm is done, and a satisfactory policy will lie between these extremes. Such a policy needs to be fully discussed and agreed and changes made in the light of experience. Despite the lack of important recent advances in managing patients with acute upper gastrointestinal bleeding we do now have a better understanding of the management that is available. We should be able to use this knowledge to improve treatment and thereby increase the chances of our patients surviving.

Consultant Physician,

Michael W DRONFIELD

Peterborough District Hospital,

Peterborough PE3 6DA

1 Cotton PB, Rosenberg MT, Waldram RPL, Axon ATR. Early endoscopy of oesophagus, stomach and duodenal bulb in patients with haematemesis and malaena. Br Med f 1973;ii:505-9.

2 Fraser GM, Rankin RN, Cummack DH. Radiology and endoscopy in acute upper gastro intestinal bleeding. BrMed F 1976; :270-1.

3 Morris DL, Hawker PC, Brearley S, Simms M, Dykes PW, Keighley MRB. Optimal timing of operation for bleeding peptic ulcer: prospective randomised trial. Br Med J 1984;288:1277-80.

4 Dronfield MW, Atkinson M, Langman MJS. Effect of different operation policies on mortality from bleeding peptic ulcer. Lancet 1979;i:1126-8.

5 Hunt PS, Francis JK, Hansky J, et al. Reduction in mortality from upper gastro-intestinal haemorrhage. Med f Aust 1983;ii:552-5.

6 Allan R, Dykes P. A study of the factors influencing mortality rates from gastro-intestina haemorrhage. $Q \mathcal{f}$ Med 1976;45:533-50.
7 Berry AR, Collin J, Frostick SP, Dudley NE, Morris PJ. Upper gastro-intestinal haemorrhage in Oxford. Fournal of The Royal College of Surgeons of Edinburgh 1984;29:134-8.

8 Dronfield MW. Medical or surgical treatment for haematemesis and malaena. Fournal of The Royal College of Physicians of London 1979;13:84-6.

9 Madden MV, Griffith GH. Management of upper gastro-intestinal bleeding in a district genera hospital. Fournal of The Royal College of Surgeons of London 1986;20:212-5.

10 Dronfield MW, Langman MJS, Atkinson M, et al. Outcome of endoscopy and barium radiography for acute upper gastro-intestinal bleeding: controlled trial in 1037 patients. BrMed f 1982;284:545-50.

11 Foster DN, Miloszewski KJA, Losowsky MS. Stigmata of recent haemorrhage in diagnosis and prognosis of upper gastro-intestinal bleeding. BrMed f 1978;i:1173-7.

12 Storey DW, Bown SG, Swain CP, Salmon PR, Kirkham JS, Northfield TC. Endoscopic prediction of recurrent bleeding in peptic ulcers. N Engl F Med 1981;305:915-6.

13 Whorewell PJ, Eade OE, Chapman R, Smith CL, Fisher JA. Comparison between admission and next-day endoscopy in the management of acute upper gastro-intestinal haemorrhage. Digestion 1981;21:18-20.

\section{Hospices for children?}

During the past decade many institutions-some termed hospices-have been established in Britain to care for adults with terminal illness. They have been started because the requirements of such patients and their relatives are not usually best met in a busy acute medical or surgical ward. In many districts buildings have been constructed or converted (within or without the National Health Service) to cater for the terminally ill, and these are supported by domiciliary medical, nursing, and other services. Such developments have been a success. So should similar services be set up for children?

Prolonged terminal illness is rarer in children than in adults. Most infants and children who die in Britain do so from acute infections or cot deaths in the first year of life or from accidents thereafter; some also die in the neonatal period from prematurity or its complications. Most district hospital children's departments have arrangements for helping the parents and relations of such patients (although the bereaved parents of children killed in accidents may not always be directed to them). Three groups of children do, however, have conditions that may cause them to die slowly: some with major congenital malformations; others with malignant disease or major organ failure resistant to treatment or for whom treatment is not suitable; and those with progressive neurodegenerative disease. The number of such children is small-perhaps half a dozen a year in a health district-but they pose substantial management problems.

Services for these families are now well established in some districts, and their success has helped others who have been developing their own. The idea of establishing hospices for children is recent: Helen House in Oxford has a national reputation, and other hospices are planned. These projects have caused concern among professionals: is there a real need for a hospice movement similar to that for adults, or is it a well intentioned but misguided idea that will result in charitable donations being made to a project of questionable benefit to children? A recent symposium sponsored by the Help the Hospices charity with the help of the Royal College of Physicians of London and the British Paediatric Association tried to answer these questions. Various schemes for helping such children and their families were discussed, and the conclusion was that plans for widespread development of such hospices should be resisted (although the absence of a consumer voice on the platform should be noted) since no more than four would be needed in Britain.

The matter should, however, be considered by health districts, which should review their services for dying 